\title{
Evaluation of the understanding the degree of diabetes decompensation in elderly patients without satisfactory glycemic control
}

\author{
Rafael Vaz Machry, Cibelle de Abreu Evaldt, Luthiele da Silva Vasconcellos, Rafaela Ramos Nunes, \\ Henrique Umpierre Pedroso, Thaymê Luísa de Souza Pires, Raquel Ferreira, Eduardo Bardou Yunes Filho, \\ Paloma Dias da Cruz, Ticiana da Costa Rodrigues
}

From 20th Brazilian Diabetes Society Congress

Porto Alegre, Brazil. 11-18 November 2015

\section{Background}

The prevalence of diabetes is increasing among the elderly. In addition to the care needed to maintain appropriate blood sugar levels, it is necessary to understand the disease. Often, this population may be more difficult to understand the risks and other factors related to the disease.

\section{Objectives}

Assess the degree of understanding of diabetes without appropriate control in elderly patients. Materials and methods: We performed a Cross study of diabetic patients in the Endocrinology Department of a Brazilian tertiary hospital who were treated between June and December 2014. We include patients over 60 yrs. of age, of both sexes, with HbA1c $\geq 8.5 \%$ using oral hypoglycemic agents and insulin. All patients underwent five questions related to satisfaction with the diet and treatment for diabetes. We reviewed the records of patients to assess the previous glycemic control.

\section{Results}

Forty-five patients were included. Glycated hemoglobin was $10.08 \pm 0.31$ (12 months before), 10.46 \pm 0.32 (six months before) and $10.34 \pm 0.22$ during the interview. When asked about the lack of clear and concrete goals in diabetes care, $40 \%$ of patients responded not have problems. Another $40 \%$ considered a serious problem. The other responded intermediate response. On "feel discouraged with the treatment," only $28 \%$ considered a serious problem and $46.7 \%$ do not consider a problem. When asked about "diet deprivation", $20 \%$ considered a serious problem, and $48.9 \%$ did not have concerns about it. We also ask if the patients were satisfied with their current treatment. $64.4 \%$ declared satisfied, and only $4.4 \%$ reported being dissatisfied. Other answering "more or less". The last question was about self-understanding of diabetes. $71.1 \%$ say understanding about their illness. Only $6.7 \%$ reported not being satisfied.

\section{Conclusion}

Despite the inappropriate glycemic control, most patients do not understand the severity and stage of disease.

\section{Acknowledgments}

Grants from Conselho Nacional de Desenvolvimento Cientifico e Tecnológico (CNPq) and Fundo de Incentivo a Pesquisa do Hospital de Clínicas de Porto Alegre (FIPE).

Published: 11 November 2015

doi:10.1186/1758-5996-7-S1-A165

Cite this article as: Machry et al.: Evaluation of the understanding the degree of diabetes decompensation in elderly patients without satisfactory glycemic control. Diabetology \& Metabolic Syndrome 2015 7(Suppl 1):A165.

\footnotetext{
* Correspondence: cievaldt@gmail.com

Universidade Federal do Rio Grande do Sul, Porto Alegre, Brazil
} 